\title{
A IMPORTÂNCIA DA AULA DE CAMPO COMO METODOLOGIA DE ENSINO DE GEOMORFOLOGIA DO SEMIÁRIDO: RELATO DE EXPERIÊNCIA NOS SERTÕES DA PARAÍBA E DO RIO GRANDE DO NORTE
}

The importance of the field class as methodology of semi-arid geomorphology teaching: report of experience in the Paraíba and Rio Grande do Norte backwoods

La importancia de la clase de campo como metodología de enseñanza de geomorfología del semiárido: relato de experiencia en los sertes de la Paraíba y del Río Grande del Norte

\author{
Joyce Ferreira Gomes ${ }^{1}$ \\ Vinicius Ferreira Luna² \\ Mirelle Oliveira Silva ${ }^{3}$ \\ Simone Cardoso Ribeiro 4
}

\begin{abstract}
RESUMO
A aula de campo é um importante recurso pedagógico para a compreensão da Geomorfologia, pois permite ao acadêmico a apreensão in loco dos conceitos geomorfológicos e, principalmente, da atuação antrópica sobre o meio natural. Nesse sentido o presente artigo tem como objetivo demonstrar a importância da aula de campo na disciplina de Geomorfologia do Semiárido, realizada nos sertões da Paraíba e do Rio Grande Do Norte com os acadêmicos do curso de Geografia da Universidade Regional do Cariri-URCA. O trabalho seguiu etapas que foram desenvolvidas no decorrer da disciplina Tópicos Especiais Geografia - Geomorfologia do Semiárido, como: Levantamento bibliográfico preliminar, Caracterização geoambiental, levantamento cartográfico da área e confecção da caderneta de campo. Ao longo da aula em campo foi possível analisar as formas derivadas dos processos morforestruturais e morfoesculturais, explicados anteriormente nas aulas da referida disciplina. Desse modo os resultados alcançados demonstraram que durante a aula realizada os alunos conseguem apreender de forma significativa Os processos e as formas observadas puderam ser mais facilmente compreendidos durante a realização da exposição em campo.

Palavras-chave: Aula de campo; Geomorfologia; Recurso pedagógico.
\end{abstract}

\footnotetext{
${ }_{1}^{1}$ Graduanda em Geografia, Bolsista de Iniciação Cientifica, Universidade Regional do Cariri - URCA, (88) 99729-2741, joycegeo.gomes@gmail.com.

2Graduando em Geografia, Bolsista de Iniciação Cientifica, Universidade Regional do Cariri - URCA, (88) 99219-2233, viniciusluna13@gmail.com.

${ }^{3}$ Graduanda em Geografia, Bolsista de Iniciação Científica. Universidade Regional do Cariri - URCA, (88) 99204-8550, mirelleoliveirasilva18@gmail.com.

4Professora Associada - DEGEO-URCA, (88) 99922-9108, simone.ribeiro@urca.br.
} 


\begin{abstract}
The field class is an important pedagogical resource for the understanding of Geomorphology, as it allows the student to apprehend in loco the geomorphological concepts and, mainly, the anthropic performance on the natural environment. In this sense, this article aims to demonstrate the importance of the field class in the discipline of Semiarid Geomorphology, held in the backlands of Paraiba and Rio Grande Do Norte with the students of the Geography course at the Regional University of CaririURCA. The work followed steps that were developed during the course. Special Topics Geography Semiarid Geomorphology, such as: Preliminary bibliographic survey, Geoenvironmental characterization, cartographic survey of the area and preparation of the field book. Throughout the classroom, it was possible to analyze the forms derived from the morphostructural and morphospultural processes, explained earlier in the classes of this discipline. Thus, the results showed that during the class held students can understand significantly the processes and the ways observed could be more easily understood during the field exposure.
\end{abstract}

Keywords: Field class; Geomorphology; Educational resource.

\title{
RESUMEN
}

La clase de campo es un recurso pedagógico importante para la comprensión de la geomorfología, ya que permite al alumno comprender in situ los conceptos geomorfológicos y, principalmente, el rendimiento antrópico en el entorno natural. En este sentido, este artículo tiene como objetivo demostrar la importancia de la clase de campo en la disciplina de Geomorfología Semiarida, realizada en las tierras de Paraíba y Rio Grande Do Norte con los estudiantes del curso de Geografía en la Universidad Regional de Cariri-URCA. El trabajo siguió los pasos que se desarrollaron durante el curso Temas especiales Geografía - Geomorfología semiárida, tales como: Estudio bibliográfico preliminar, caracterización geoambiental, estudio cartográfico del área y preparación del libro de campo. A lo largo del aula, fue posible analizar las formas derivadas de los procesos morfoestructurales y morfospulturales, explicados anteriormente en las clases de esta disciplina. Por lo tanto, los resultados mostraron que durante la clase impartida los estudiantes pueden comprender significativamente los procesos y las formas observadas podrían entenderse más fácilmente durante la exposición en el campo.

Palabras clave: Lección de campo; Geomorfología; Recurso pedagógico.

\section{INTRODUÇÃO}

A Geomorfologia pode ser entendida como o estudo das formas da Terra. Nessa perspectiva, para estudar a Geomorfologia é importante considerar como integrante de seu objeto de estudo os processos responsáveis pelas ações capazes de criar ou destruir as formas de relevo (GUERRA; CUNHA, 2007).

Neste sentido, para a análise dessas estruturas e processos que moldam o relevo, é essencial o trabalho de campo, uma vez que este recurso nos possibilita uma maior e melhor compreensão dos conteúdos repassados. Como ressaltam Barboza e Rodrigues (2016) através do campo é possível chegar a essa compreensão, pois o aluno poderá ter uma visão mais minuciosa sobre a realidade na qual está inserido, ou seja, poderá observar in loco todas as transformações, dinâmicas e relações existentes naquele espaço.

Dentro da Geografia o trabalho de campo é bastante utilizado, tendo grande importância para o ensino, pois os espaços fora da sala de aula despertam a mente e a capacidade de aprender, pois se caracterizam como espaços estimulantes que, se bem aproveitados, se classificam como um relevante cenário para a aprendizagem (CARBONELL, 2002). Como afirma Libâneo (1994, p. 71) "todos esses Revista da Casa da Geografia de Sobral, Sobral/CE, v. 21, n. 2, Dossiê: Estudos da Geografia Física do Nordeste brasileiro, p. 784-794, Set. 2019, http://uvanet.br/rcgs. ISSN 2316-8056 @ 1999, Universidade Estadual Vale do Acaraú. Todos os direitos reservados. 
procedimentos que permitem uma discussão em torno do mundo concreto do aluno devem ser enriquecidos com visitas às localidades abordadas".

Sabe-se que é importante aplicar a teoria na prática, por isso a aula de campo é sempre necessária, visto que é um instrumento metodológico que alia os conhecimentos obtidos em sala de aula com observações in loco. Pensando nisso, o presente artigo objetivou demonstrar a importância da aula de campo na disciplina de Geomorfologia do Semiárido, a qual ocorreu nos estados da Paraíba e o Rio Grande do Norte, pois em ambos pode-se observar explicitamente os fenômenos que ocorrem na região semiárida nordestina.

Nos estados acima citados, foram visitados os municípios de Patu, Martins, Currais Novos, Carnaúba dos Dantas e Caicó localizados no Rio Grande do Norte e Patos, Teixeira e Sousa, na Paraíba, como mostrado na Figura 1; a aula foi realizada com o intuito de visualizarmos unidades de relevo moldados por processos relacionados ao clima seco do sertão da região Nordeste.

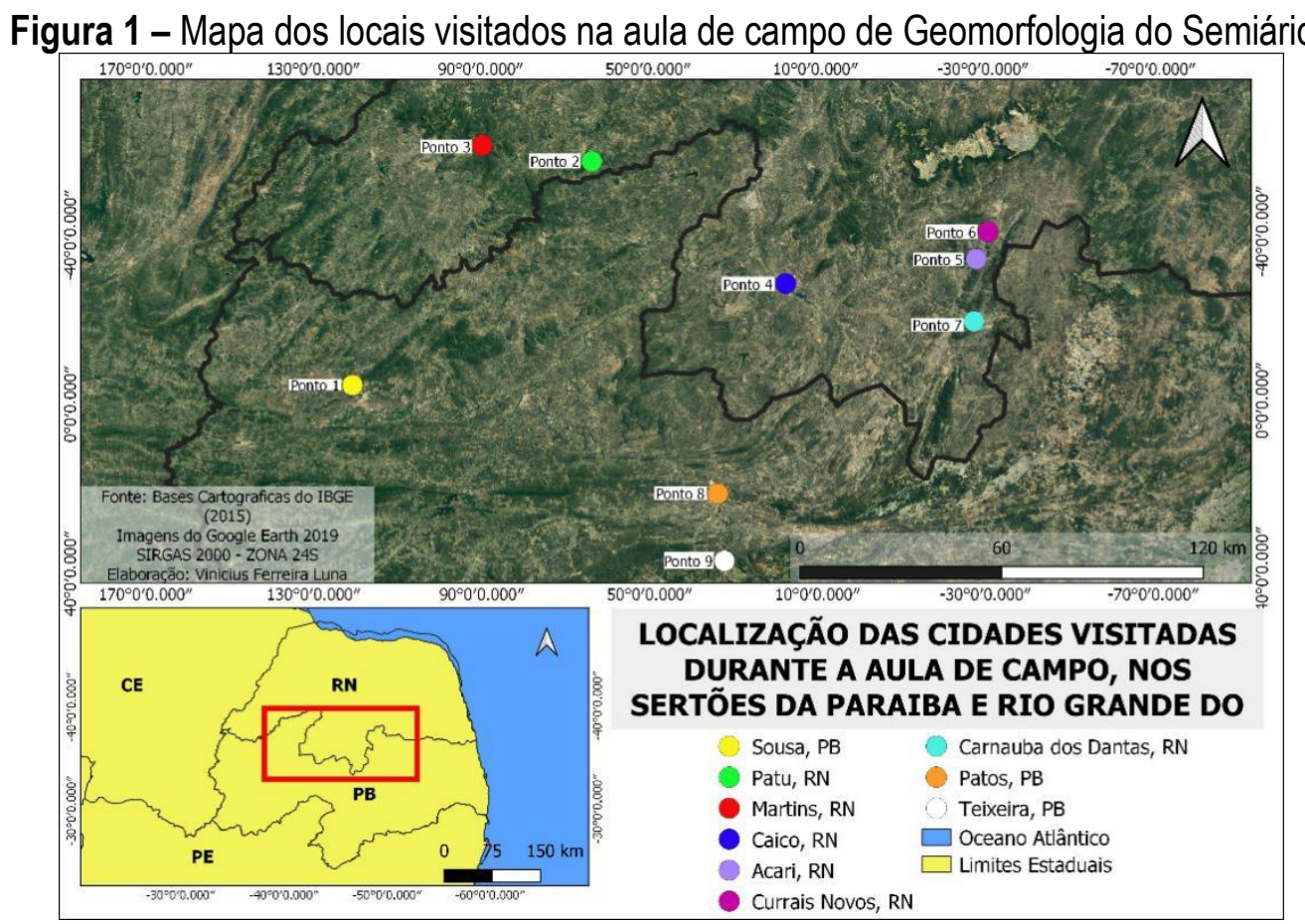

Fonte: Luna, (2019)

Os estados do Rio Grande do Norte e da Paraíba estão localizados no Nordeste brasileiro limitando-se ao sul com estado de Pernambuco, a oeste com estado do Ceará, e a leste e norte com o Oceano Atlântico. A Paraíba possui 56.584,6 km², e o Rio Grande do Norte 52.797 km², sendo boa parte de seu relevo composto pelo Planalto da Borborema e pela Depressão Sertaneja.

O semiárido nordestino caracteriza-se por possuir clima seco com índices pluviométricos baixos, além de apresentar unidades morfoesculturais e morfoestruturais definidas, sendo as primeiras, típicas 
de regiões com déficit hídrico. Diante disso, a aula foi realizada para que pudéssemos observar os processos geomórficos exógenos discutidos, em teoria, na sala de aula. Pôde-se destacar, em campo, a ação do clima no relevo, as litologias, os processos fluviais e de pediplanação, o intemperismo (físico e químico), além de identificar as principais unidades de relevo do semiárido.

O Nordeste brasileiro tem uma grande variedade de unidades geomorfológicas que se desenvolveram de acordo com os processos de morfoestruturação e morfoesculturação, ocasionados por processos endógenos e exógenos que por sua vez implicam na transformação da paisagem. Segundo Bastos e Cordeiro (2012 p.469):

Pode-se destacar um predomínio das depressões sertanejas como unidade geomorfológica, porem existe inúmeras feições residuais, como campos de inselbergs maciços cristalinos, relevos formados em bacias sedimentares, como cuestas, planaltos, morros testemunhos e depressão periférica, além de planícies de deposição sedimentar cenozoica como terraços fluviais e os tabuleiros pré-litoraneos (glacis). A evolução geomorfológica do semiárido brasileiro se deu a partir do predomínio de processos de intemperismo físico. Nessa perspectiva, existe um consenso que essas áreas passam a sofrer processos de aplainamento, formando vastas superfícies de erosão (pediplanos sertanejos). A limitada competência e capacidade dos rios semiáridos em entalhar vales faz com que as superfícies sertanejas se apresentem suavemente onduladas com pequenas amplitudes altimétricas entre os fundos de vales e os interflúvios.

Os Estados do Rio Grande do Norte e da Paraíba apresentam características de vegetação predominantes da Caatinga (Figura 2), um bioma exclusivamente brasileiro, com diferentes fisionomias de acordo com o grau de xeromorfismo. 0 tipo de caatinga mais presente nesses dois estados é do tipo hiperxerófila, a mesma trata-se de um tipo de vegetação mais seca, rala, de porte baixo, desenvolvida em solo pedregoso e pouco desenvolvido, possuindo um grau maior de xerofitismo, que seria a resistência e adaptação das plantas à falta de água.

Figura 2 - Vegetação no período seco, na região do Seridó, no estado do Rio Grande do Norte.

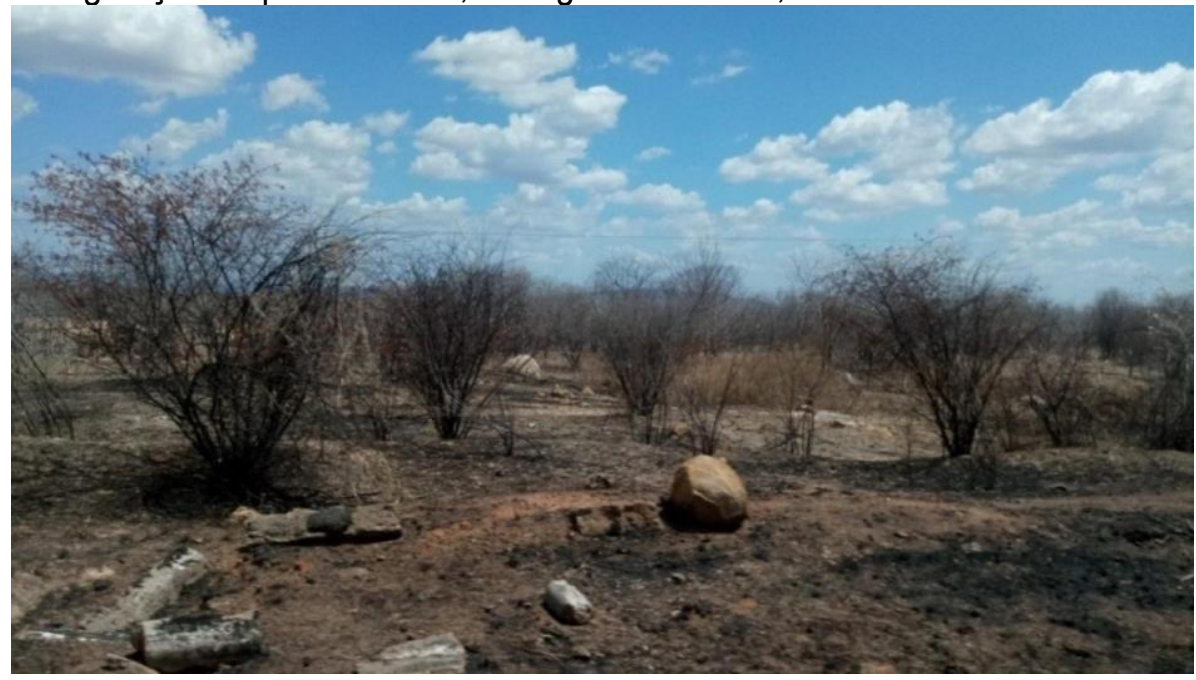

Fonte: Silva (2017) do Nordeste brasileiro, p. 784-794, Set. 2019, http://uvanet.br/rcgs. ISSN 2316-8056 @ 1999, Universidade Estadual Vale do Acaraú. Todos os direitos reservados. 
Diante do exposto, o presente artigo objetivou demonstrar a importância da aula de campo na disciplina de Geomorfologia do Semiárido tendo como ambiente natural o sertão da Paraíba e do Rio Grande Do Norte, com a participação dos acadêmicos do curso de licenciatura em Geografia da Universidade Regional do Cariri.

\section{MATERIAL E MÉTODO}

O trabalho de campo seguiu algumas etapas para seu desenvolvimento ao longo da disciplina Tópicos Especiais em Geografia - Geomorfologia do Semiárido, ofertada no curso de Geografia da Universidade Regional do Cariri-URCA. Entre os procedimentos realizados estão: o levantamento bibliográfico que foi baseado em autores como Christofoletti (1980), Penteado (1983), Casseti (2005), Souza, (2006), Claudino-Sales e Peulvast (2007), Jatobá e Lins (2008), Ribeiro; Marçal e Correa (2010), Guerra e Guerra (2011), Bastos e Cordeiro (2012).

Houve a etapa de caracterização geoambiental, levantamento cartográfico da área e confecção da caderneta de campo. Para se estudar um ambiente é essencial uma caracterização ambiental (geologia-geomorfologia, clima, solos, hidrografia e vegetação) da área de estudo (Paraíba e Rio Grande do Norte) pois os elementos naturais fornecem dados que auxiliam nas análises e facilitam no momento do campo. A caracterização teve como principal auxiliar o projeto RADAMBRASIL (BRASIL, 1981).

O campo foi concebido como uma das etapas mais importantes para a disciplina, uma vez que nele se daria a efetivação da compreensão daquilo que foi apresentado e discutido em sala. Nesta etapa, o principal foco foi perceber os processos e formas dos sertões da Paraíba e do Rio Grande do Norte. Durante a aula, ao longo do percurso foram realizadas 09 paradas, com o intuito de analisar, discutir e reconhecer pontos específicos: Souza-PB, Patu-RN, Martins-RN, Caicó-RN, Currais Novos-RN, AcariRN, Carnaúba dos Dantas-RN, Patos-PB e Teixeira-PB.

Em geral foram observados a litologia, ação do intemperismo, os processos de pediplanação com unidades geomórficas típicas, formações rochosas, processos fluviais típicos de regiões semiáridas, microclima, áreas de desertificação e outros aspectos característicos dos sertões percorridos. Ao final, os acadêmicos produziram relatórios, no qual puderam demonstrar os conhecimentos adquiridos durante a aula de campo.

\section{RESULTADOS E DISCUSSÃO}

Durante o percurso da aula de campo foram observadas unidades morfoestruturais e morfoesculturais, conceitos criados para designar unidades de relevo que se formam a partir de 
estruturas geológicas (produzidas por energias endógenas), e por processos erosivos e deposicionais (esculpidos por energias exógenas).

Segundo Jatobá e Lins (2008) nas morfoestruturas podem ser observados os principais aspectos de desenvolvimento regional, pois em diversos casos, as morfoestruturas são controladas por levantamento ou subsidência tectônicos ocorridos na área. As morfoesculturas, em seu turno, se originam a partir das influências dos processos erosivos e de deposição. Assim, encontram-se muito dependentes das condições climáticas. Mediante os conceitos expostos, ao observarmos o relevo como um todo, podemos destacar as unidades morfoestruturais e morfoesculturais, uma vez que estas se destacam na paisagem.

Para explicar os processos morfoesculturadores da paisagem Guerra e Guerra (2011) afirmam que a Geomorfologia Climática é o estudo das formas de relevo comandadas pelo clima. Nessa perspectiva, em climas úmidos teremos um tipo de relevo com características especificas, tendo a atuação do intemperismo químico predominante que ocorre em locais com totais pluviométricos altos e bem distribuídos, e em áreas secas teremos outros tipos de relevo com ação predominante do intemperismo físico que ocorrem em locais com a pluviometria baixa e concentrada, como é o caso do semiárido. O semiárido nordestino caracteriza-se por apresentar totais pluviométricos que não ultrapassem a isoieta de $800 \mathrm{~mm}$ e pela existência de longos e persistentes períodos de estiagem, ainda de difícil previsibilidade absoluta. (RIBEIRO, MARÇAL, CORREA 2010).

No semiárido, as duas unidades podem ser observadas, sendo a morfoescultural a mais focada na aula de campo, pois ela molda o relevo através de processos exógenos, essencialmente pelo déficit de umidade, onde identificamos o intemperismo físico predominante, e à violência das enxurradas devido à concentração pluviométrica. Na Serra do Lima, localizado no município de Patu/RN, o intemperismo físico é facilmente observado. As rochas encontradas são intensamente quebradas devido principalmente à ação do sol e da oscilação de temperatura (termoclastia), provocando uma acentuada desagregação. Embora a meteorização física predomine, a presença do químico ainda é notada, pois a vegetação pioneira nas fendas de rochas na Serra do Lima produz um acúmulo de umidade e um intemperismo químico um pouco mais significativo. 
Figura 3: Ação do Intemperismo físico e químico na Serra do Lima-RN

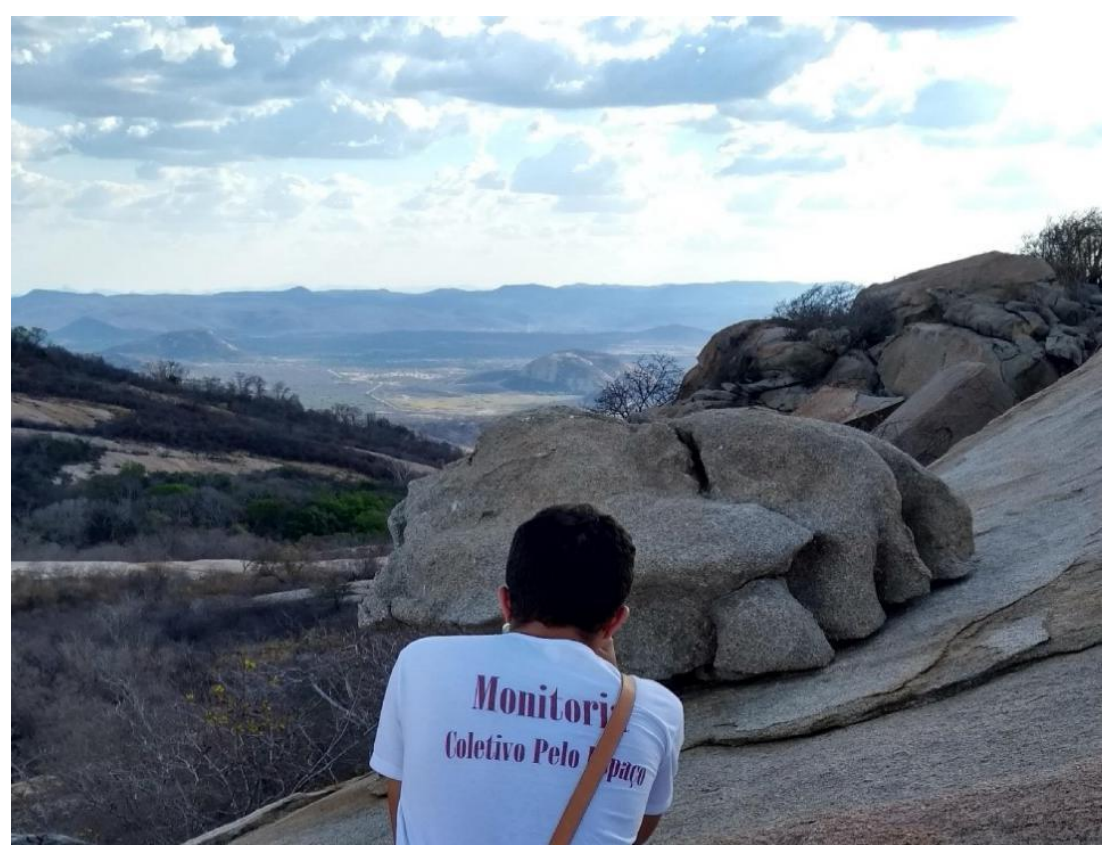

Fonte: Luna (2017)

Outro processo morfoescultural observado em regiões semiáridas é a pediplanação. Este processo, quando levado a termo durante tempo suficiente, leva ao total aplainamento, na qual as regiões de clima árido e semiárido passam a desenvolver áreas sem grande movimentação do relevo, conhecidas como os pediplanos. Cidades visitadas onde essas formas podem ser observadas com clareza são Teixeira na Paraíba, Patu e Carnaúba dos Dantas no estado do Rio Grande do Norte, como mostra a figura 5 .

Figura 4: Aplainamento observado da Serra do Lima, Patu-RN

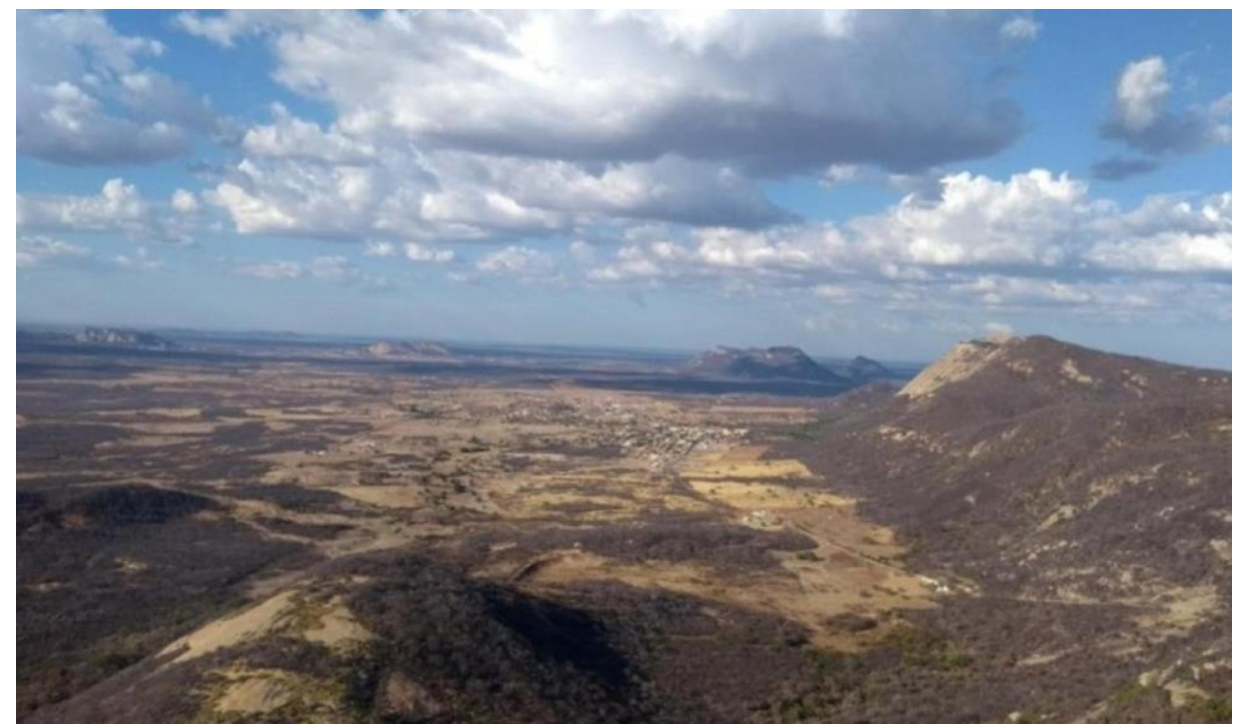

Fonte: Luna (2017) do Nordeste brasileiro, p. 784-794, Set. 2019, http://uvanet.br/rcgs. ISSN 2316-8056 @ 1999, Universidade Estadual Vale do Acaraú. Todos os direitos reservados. 
Os inselbergues também foram observados e destacados no grande aplainamento, sendo uma resposta morfoestrutural aos processos exógenos, já que foram formados através de eventos internos, como intrusões, e destacados na paisagem devido à erosão diferencial. Segundo a definição do Dicionário Geológico-Geomorfológico (GUERRA e GUERRA, 2011), inselbergues são como resíduos da pediplanação, em climas áridos quentes e semiárido. Em grande parte das cidades visitadas pode-se observar essas formas de relevo, pois são comuns de regiões semiáridas, como mostra a figura 7.

Figura 5: Inselbergue próximo a cidade de Patos, no Estado da Paraíba

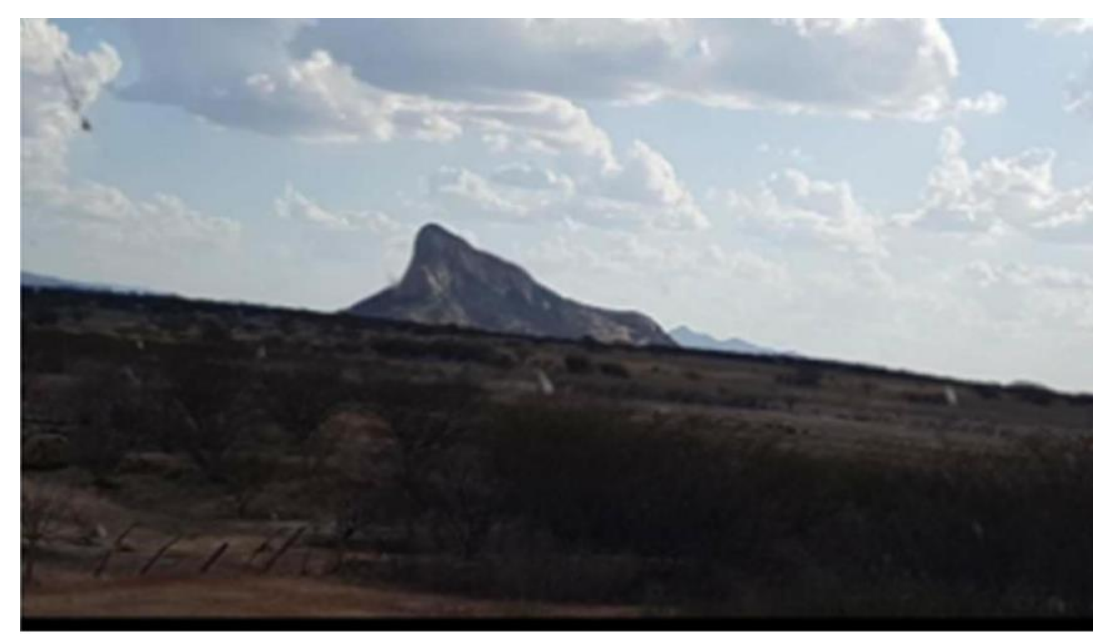

Fonte: Gomes (2017)

Outra morfoestrutura que observamos foi o Planalto da Borborema, área que abrange 4 estados, Alagoas, Paraíba, Rio Grande do Norte e Pernambuco, sendo um relevo marcado por uma abóbada dissecada em conjuntos de serras e vales, localizando-se ao lado da Depressão Sertaneja. A aula estendeu-se até a Pedra do Tendó, localizado no município de Teixeira no estado da Paraíba, a qual faz parte Borborema. Nesta área visitada pode ser observado a Depressão Sertaneja do município de Patos/PB (Figura 8).

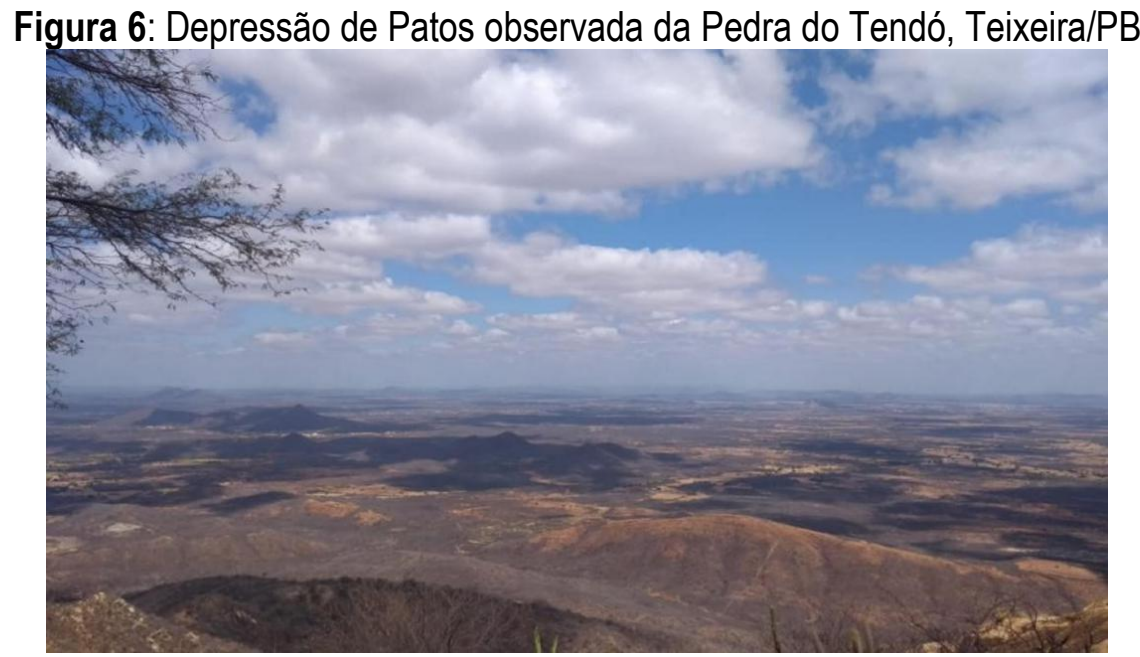

Fonte: Gomes (2017) do Nordeste brasileiro, p. 784-794, Set. 2019, http://uvanet.br/rcgs. ISSN 2316-8056 @ 1999, Universidade Estadual Vale do Acaraú. Todos os direitos reservados. 
Em áreas semiáridas, os rios produzem seus vales, essencialmente, através do processo de erosão lateral, o que ocorre nas suas margens, intensificando à medida que aumenta a quantidade e a velocidade da água no canal fluvial (GUERRA e GUERRA, 2011). No Nordeste brasileiro a erosão lateral dos canais fluviais está relacionada ao tipo climático, pois rios situados em regiões semiáridas, que apresentam baixas vazões e fluxo sazonal, os processos erosivos são observados com maior magnitude em épocas de chuvas acima da média, contribuindo, para o alargamento do canal (ANDRADE, 2016), resultando em leitos de fundo chato com laterais íngremes, como o exemplo observado em campo do Rio Seridó em Caicó-RN.

Figura 7: Rio Seridó, Caicó - RN

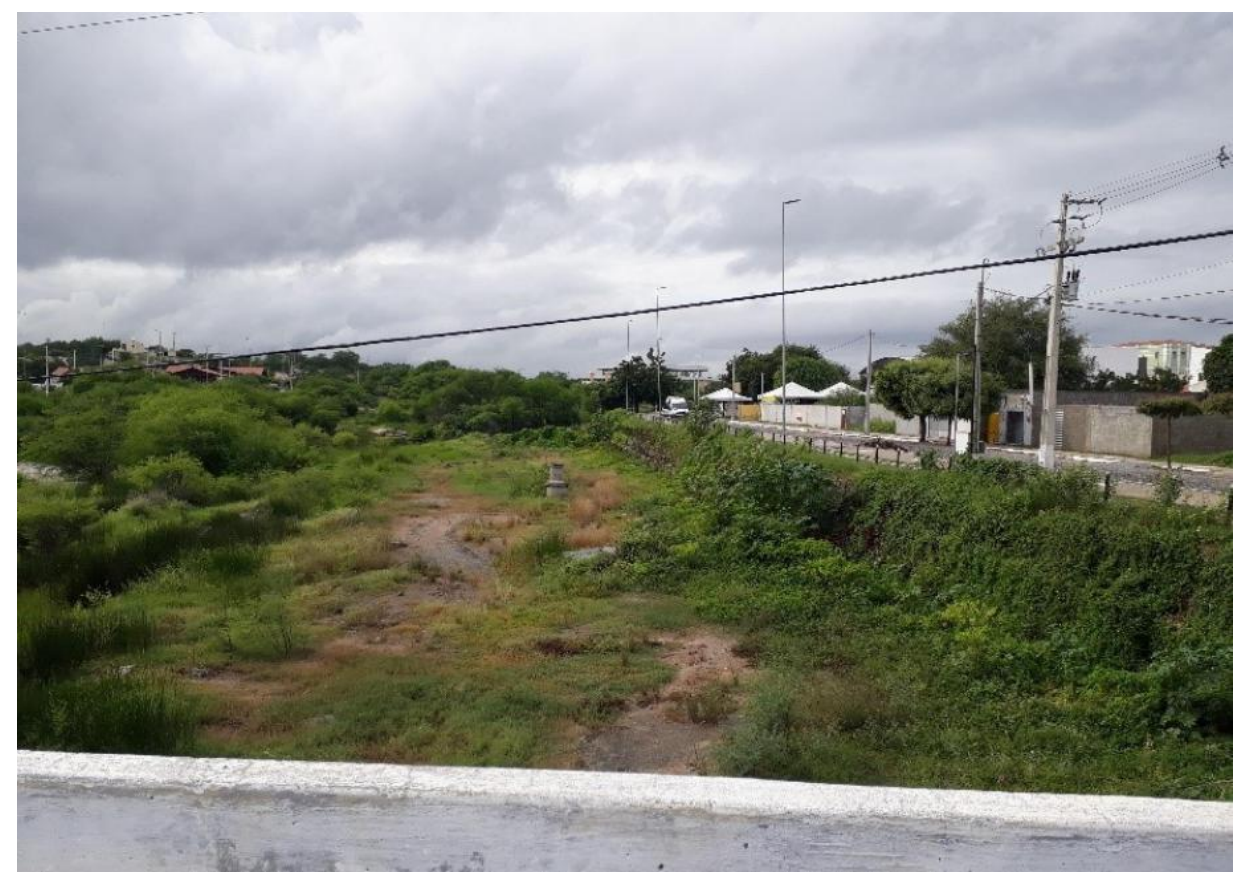

Fonte: Silva (2019)

Foi observado também o pavimento desértico dos solos que são depósitos oriundos de regiões desérticas composto de fragmento rochosos, seixos e matacões, decorrente da retirada dos finos dos solos pela erosão laminar. Outro aspecto que foi observado durante a aula, foram as caneluras nas rochas das serras, originadas pelos fluxos de água que acabam desgastando os minerais e produzindo as reentrâncias. 
Figura 8: Caneluras observadas na Serra do Lima, Patu-RN

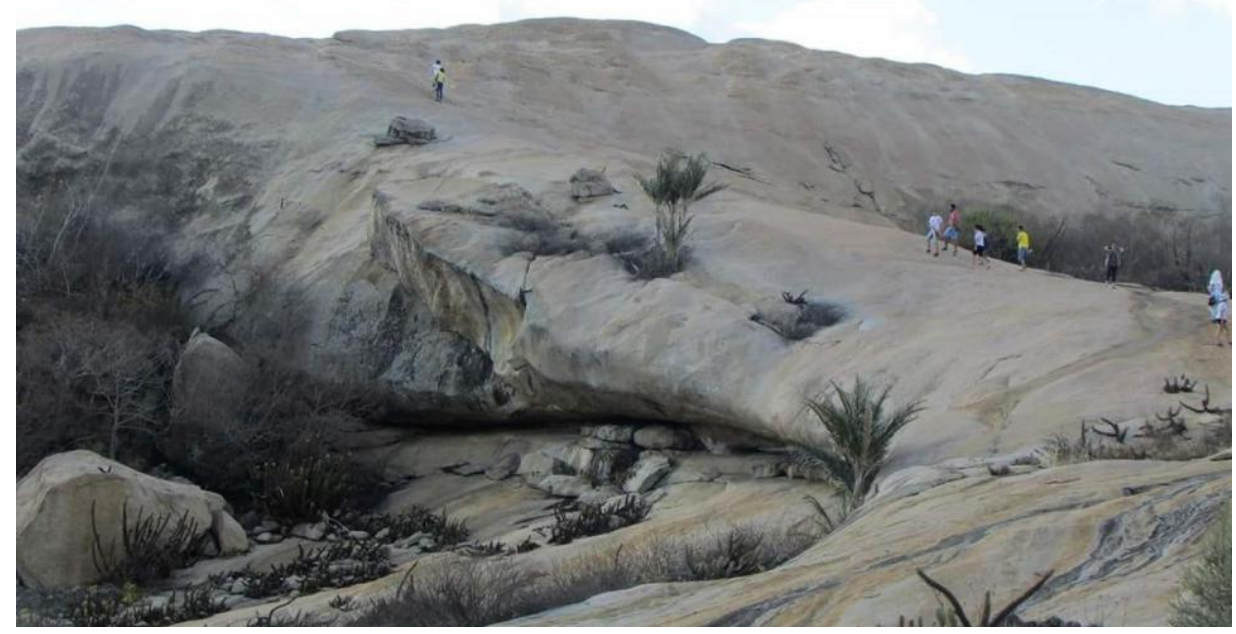

Fonte: Carlos Jefferson (2017)

\section{CONSIDERAÇÕES FINAIS}

O presente trabalho foi realizado mediante as observações e conclusões feitas em campo, durante os dias das aulas ocorridas nos estados da Paraíba e do Rio Grande do Norte. Neste trabalho percebemos de fato a contribuição da aula de campo, pois através dela parte do ambiente semiárido pôde ser conhecido e melhor interpretado. A análise empírica da paisagem é um fator decisivo para a compreensão dos processos que operam na superfície, já que cada processo se configura de maneira diferente na paisagem.

$\mathrm{Na}$ aula, foi esclarecida a maneira como operam os processos geomórficos em regiões semiáridas, como ocorre a pediplanação, a formação de inselbergues, como atuam o intemperismo físico e o químico, assim como há a predominância do físico. Foram observadas também as dinâmicas fluvial e climática da região, além de destacarmos os tipos de rochas presentes, os solos desenvolvidos e os processos erosivos atuantes nos ambientes, entre outros aspectos.

Com isso, percebe-se a importância que possui a aula de campo, principalmente quando se trata da ciência geomorfológica, pois contribui para a formação contextualizada, possibilitando um vasto conhecimento sobre o ambiente semiárido. 


\section{REFERÊNCIAS}

ANDRADE, J. H. R. Dinâmica de margens em rios semiáridos: aplicações metodológicas no rio Jaguaribe. Dissertação (MESTRADO EM AMBIENTE, TECNOLOGIA E SOCIEDADE) - Universidade Federal Rural do Semiárido. Mossoró, 2016. Disponivel em: https://ppgats.ufersa.edu.br/wpcontent/uploads/sites/47/2016/05/Disserta\%C3\%A7\%C3\%A30-Jos\%C3\%A9Hamilton-Ribeiro-Andrade.pdf. Acesso em 21/08/2018.

BARBOZA, B.S.S. RODRIGUES, H.M. Prática de ensino: A importância da aula de campo em disciplinas acadêmicas para formação docente em geografia. XVIII Encontro Nacional de Geógrafos, São Luiz/Maranhão, 2016.Anais. São Luís: 2016.

BASTOS, F. H.: CORDEIRO, A. M. Fatores naturais na evolução das paisagens no semiárido brasileiro: uma abordagem geral. Revista Geonorte, Edição Especial, v.2, n. 4, P. 464-476.2012. Disponível em: http://www.periodicos.ufam.edu.br/revistageonorte/article/view/2099/1974. Acesso em 21/08/2018.

BRASIL, Ministério das Minas e Energia. Secretaria-Geral. Projeto RADAMBRASIL. Folhas SB. 24/25 Jaguaribe/Natal; geologia, geomorfologia, pedologia, vegetação, uso potencial da terra. Rio de Janeiro, 744p.1981.

CARBONELL, J. A aventura de inovar: a mudança na escola. Porto Alegre: Artmed, 2002 (Coleção Inovação Pedagógica). CASSETI, Valter. Geomorfologia. [S.I.]: [2005]. Disponível em: http://www.funape.org.br/geomorfologia/.

CHRISTOFOLETTI, A. Geomorfologia. 2.ed. São Paulo: Edgard Blücher, 188p.1980.

CLAUDINO-SALES, V. e PEULVAST. J-P. Evolução morfoestrutural do relevo da margem continental do estado do Ceará, Nordeste do Brasil. Caminhos de Geografia. Uberlândia v. 7, n. 20 Fev/2007 p. 1 - 21.

GUERRA, A.J.T.; CUNHA, S.B. (Org.). Geomorfologia: uma atualização de bases e conceitos. 7ed. Rio de Janeiro: Bertrand Brasil,

2007. Instituto Brasileiro de Geografia e Estatística - IBGE. Manual Técnico de Geomorfologia. Rio de Janeiro: IBGE, 1994. (Manuais Técnicos em Geociências).

GUERRA, A. T. GUERRA, A. J. T. Novo dicionário geológico-geomorfológico. $9^{\circ}$ ed. Rio de Janeiro: Bertrand Brasil. 648p.2011.

JATOBÁ, L. e LINS, R. C. Introdução a geomorfologia. Recife: Ed. Bagaço, 5ª Ed., 2008.

LIBÂNIO, J. C. Didática. São Paulo: Cortez, 1994. (Coleção Magistério $2^{\circ}$ Grau. Série Formação do professor).

PENTEADO, M.M. Fundamentos de Geomorfologia. Rio de Janeiro: IBGE, 185p.1983.

RIBEIRO, S.C; MARÇAL, M.S. e CORREA, A.C.B. Geomorfologia de áreas semi-áridas: uma contribuição ao estudo dos sertões nordestinos. Revista de Geografia. Recife: UFPE-DCG/NAOA, v.27, n.1, jan/mar. P. 120-137. 2010.Disponivel em: https://periodicos.ufpe.br/revistas/revistageografia/article/view/228790. Acesso em 21/08/2018.

SOUZA, M. J. N., Contexto Geoambiental do Semi-Árido do Ceará: Problemas e perspectivas. In: SOBRINHO, J. Falcão; FALCÃO, Cleire. L. da Costa. (Org.). Semi-Árido: Diversidades, fragilidades e potencialidades. Sobral: Sobral Gráfica, 2006. p. 14-33. 